\title{
The one microgram adrenocorticotropin test in the assessment of hypothalamic-pituitary-adrenal function
}

\author{
Bruno Ambrosi, Laura Barbetta, Tiziana Re, Elena Passini and Giovanni Faglia \\ Institute of Endocrine Sciences, University of M ilano, Ospedale M aggiore IRCCS, M ilano, Italy \\ (Correspondence should be addressed to B A mbrosi, Institute of Endocrine Sciences, Ospedale M aggiore IRCCS, via F. Sforza, 35 - 20122 M ilan, Italy)
}

\begin{abstract}
The possibility of assessing hypothalamic- pituitary-adrenal (HPA) function by the standard ACTH test $(250 \mu \mathrm{g})$ has been widely discussed in the past years and compared with the role of the insulin tolerance test (ITT). Recently, it was shown that low doses of ACTH, such as $1 \mu \mathrm{g}$ i.v., induce a maximal adrenal response and, by reducing the discrepancies compared with the ITT also allow one to detect mild forms of secondary hypoadrenalism. In the present study the $1 \mu \mathrm{g} \mathrm{ACTH}$ test was performed in patients with hypothalamic- pituitary disease in order to assess adrenal function, and the results have been compared with those obtained after the insulin test. Fifty-seven patients ( 31 men and 26 women, aged 19-73 years) with hypothalamic- pituitary diseases were studied: 51 patients were affected with pituitary tumor and 6 patients had hypothalamic disorders. All these patients and 18 healthy volunteers ( 7 men and 11 women, aged 19-46 years) received $1 \mu \mathrm{g}$ i.v. ACTH injection. In addition, the ITT $(0.1-0.15 \mathrm{U} / \mathrm{kg}$ body weight) was performed in all patients. In normal subjects mean cortisol levels significantly $(P<0.001)$ increased from a baseline of $393 \pm 43 \mathrm{nmol} / \mathrm{l}$ to a peak of $770 \pm 41 \mathrm{nmol} / \mathrm{l}$ after $1 \mu \mathrm{g} \mathrm{ACTH}$. In 44 patients with hypothalamic-pituitary disease $1 \mu \mathrm{g} \mathrm{ACTH}$ caused a cortisol rise similar to that of normal subjects (from $332 \pm 17$ to $769 \pm 24 \mathrm{nmol} / \mathrm{l}$; $\mathrm{P}<0.001$ ), while an impaired response (from $124 \pm 23$ to $312 \pm 46 \mathrm{nmol} / \mathrm{l}$ ) was observed in 13 cases $(23 \%), 7$ of them with low morning cortisol levels $(10-127 \mathrm{nmol} / \mathrm{l})$ and 6 with basal values at the lower limit of normality. The cortisol response to ITT was compared with that obtained after the $1 \mu \mathrm{g} \mathrm{ACTH}$ test: 10 patients failed both challenges, 4 patients who passed the ACTH test failed the ITT, while 3 patients who failed the ACTH test passed the ITT. The 23 out of 57 patients $(40 \%)$ who showed a cortisol peak greater than $750 \mathrm{nmol} / \mathrm{l}$ after $1 \mu \mathrm{g} \mathrm{ACTH}$ had a normal response to ITT. A positive correlation between cortisol peaks after ACTH and after insulin was also found $(r=0.68, P<0.001)$. Assuming a $100 \%$ accuracy of ITT, the low dose ACTH test yielded a $71 \%$ sensitivity and a $93 \%$ specificity.

In conclusion, the low-dose ACTH test is a useful, safe and in expensive tool for the initial assessment of HPA function in patients with hypothalamic- pituitary disease. In fact, the ITT is unnecessary when cortisol peaks are greater than $750 \mathrm{nmol} / \mathrm{l}$ after $1 \mu \mathrm{g} \mathrm{ACTH}$ and also when very low cortisol basal levels indicate an overt hypoadrenalism. Within these limits the ITT is mandatory and its important role in the recognition of secondary adrenal failure is further confirmed.
\end{abstract}

European Journal of Endocrinology 139 575-579

\section{Introduction}

The usefulness of the adrenocorticotropin (ACTH) test in the evaluation of the hypothalamic-pituitaryadrenal (HPA) axis in patients with suspected secondary hypoadrenalism has been widely discussed.

In the past, several studies have shown that the short Synacthen test (SST), performed with the standard dose of $250 \mu \mathrm{g}$, was able to replace the insulin tolerance test (ITT) in the detection of secondary hypoadrenalism (1 5 ). Although the SST only measures the functional integrity of the adrenal gland, it also provides an indirect assessment of the integrity of HPA function in conditions of chronic corticotropin deficiency, owing to the correlation between peak cortisol levels after $250 \mu \mathrm{g}$ ACTH and after ITT (1-5). However, it has been questioned whether the use of a supraphysiological dose, such as $250 \mu \mathrm{g}$, may give false positive results, particularly in conditions of partial ACTH deficiency, and it is not always correlated with the response to stress (6-9). Therefore, the ITT, despite its well-known contraindications, maintains its prominent role and is still regarded as the gold standard for the evaluation of the HPA axis.

Recently, it has been shown that in normal subjects a maximal adrenal response can be obtained with smaller doses of ACTH $(0.5,1,5 \mu \mathrm{g})$ that may induce the release of immediately available cortisol, while the higher dose 
of $250 \mu \mathrm{g}$ probably causes further cortisol synthesis $(10-12)$. Since the dose of $1 \mu \mathrm{g}$ allows either the detection of mild forms of secondary hypoadrenalism that escape detection by the conventional SST, or the reduction of the discrepancies between ITT and SST, the challenge has been recommended as a preliminary screening procedure $(13,14)$. So far, the usefulness of a low dose ACTH test in the diagnosis of secondary hypoadrenalism has been evaluated in patients with hypothalamic-pituitary disorders (15-18) and in patients taking inhaled corticosteroids $(19,20)$.

Recent findings of a close association between cortisol responses to $1 \mu \mathrm{g} \mathrm{ACTH}$ and ITT in a small number of subjects with hypothalamic- pituitary disease (15-17), prompted us to study a large group of these patients. The aim of the present work was to evaluate the role of $1 \mu \mathrm{g} \mathrm{ACTH}$ in the assessment of adrenal function and to compare the results to those obtained after the insulin test in order to identify the proper role of each challenge.

\section{Subjects and methods}

\section{Subjects}

Fifty-seven patients (31 men and 26 women, aged 19 73 years) with hypothalamic-pituitary diseases were studied. Fifty-one patients had a pituitary tumor: 25 cases were affected with acromegaly, 15 with nonfunctioning adenoma, 10 patients had a prolactinoma and 1 had a follicle-stimulating hormone-secreting tumor. Six patients had hypothalamic disorders of various etiology: 3 cases had craniopharyngioma, 1 had an astrocytoma, 1 had a hamartoma, and 1 had a cyst of Rathke's pouch. Twelve patients were evaluated before treatment, while another forty-five cases were investigated after pituitary surgery (performed from 1 month up to 312 months) or radiation therapy. Patients with Cushing's disease were excluded. Fifteen patients were receiving steroid replacement treatment from 1168 months (median 30 months); they tapered the dose and stopped the therapy at least $48 \mathrm{~h}$ before being investigated.

Eighteen healthy volunteers ( 7 men and 11 women, aged 19-46 years) recruited from the medical staff served as controls.

Informed consent was obtained from both patients and normal subjects.

\section{Testing protocols}

The low dose ACTH test was performed by the administration of $1 \mu \mathrm{g}$ tetracosactrin (Synacthen, Ciba, Origgio, Italy) into an antecubital vein between $0800 \mathrm{~h}$ and $0900 \mathrm{~h}$. Blood samples for cortisol determination were taken at $0,30,40$ and $60 \mathrm{~min}$ after the injection. A stock solution of $5 \mu \mathrm{g} / \mathrm{ml}$ was kept at $4{ }^{\circ} \mathrm{C}$ in glass tubes. A concentration of $1 \mu \mathrm{g} / \mathrm{ml}$ was obtained by

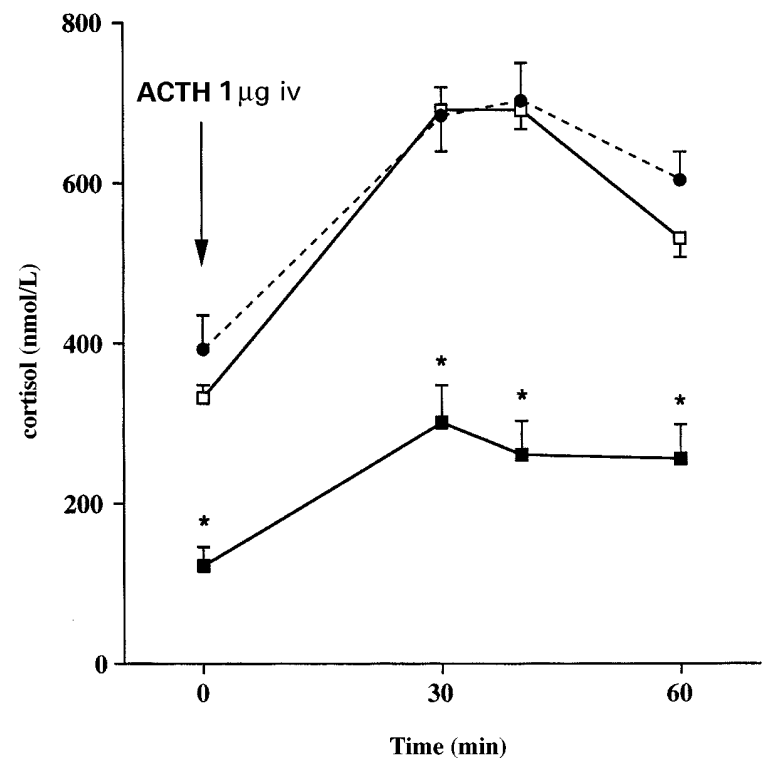

Figure 1 Serum cortisol (means \pm S.E.M.) modifications after ACTH $(1 \mu \mathrm{g}$ i.v. $)$ in 44 responsive patients with hypothalamic-pituitary diseases (solid line, open squares), in 13 non-responsive patients (solid line, closed squares) and in 18 normal subjects (dotted line, closed circles). The asterisks indicate the significance between nonresponsive patients and normal subjects $(P<0.001)$.

further dilution in a sterile saline solution, immediately before injection.

The insulin tolerance test was carried out by the i.v. administration of $0.1-0.15 \mathrm{U} / \mathrm{kg}$ body weight of shortacting human insulin after an overnight fast. Samples for cortisol and glucose determination were taken at 0 , $30,45,60,90 \mathrm{~min}$. The hypoglycemia was considered as adequate when a nadir serum glucose lower than $2.2 \mathrm{mmol} / \mathrm{l}(40 \mathrm{mg} / \mathrm{dl})$ was achieved. Criteria for normal responses to ITT were peak cortisol values greater than $500 \mathrm{nmol} / \mathrm{l}(2-4,21,22)$.

There were no serious adverse events during ACTH and insulin tests in any of the subjects. The tests were performed in a randomized order.

\section{Hormone measurements}

Serum cortisol $(1 \mathrm{nmol} / \mathrm{l}=0.0362 \mu \mathrm{g} / \mathrm{l})$ levels were measured on unextracted samples by an RIA method (Diagnostic Products, Los Angeles, CA, USA). The intraand interassay coefficients of variation were $7.3 \%$ and $5.4 \%$ respectively; the lower limit of sensitivity was $11 \mathrm{nmol} / \mathrm{l}$. In our laboratory the limits of normality were $140-700 \mathrm{nmol} / \mathrm{l}$. All samples from a given patient were measured in the same assay.

\section{Statistical analysis}

The data, expressed as means \pm S.E., were analyzed using paired or un paired $t$-test, as appropriate, and by the ANOVA test for repeated measures followed by Scheffe 


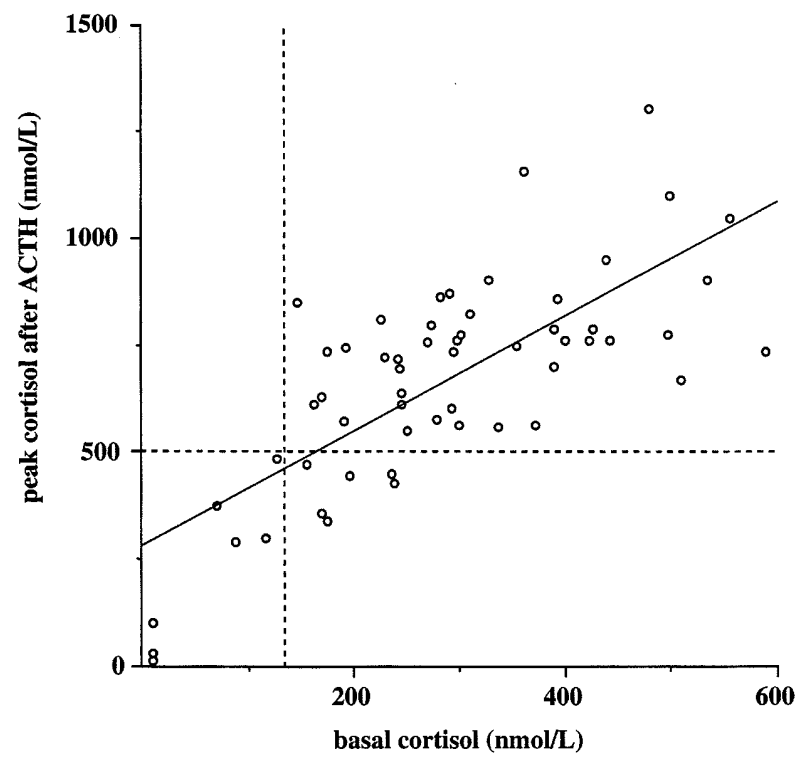

Figure 2 Correlation between peak serum cortisol concentrations after ACTH (1 $\mu \mathrm{g}$ i.v.) and basal cortisol levels in 57 patients with hypothalamic-pituitary diseases $(r=0.74, P<0.001)$. Dotted lines indicate normal ranges: the vertical line shows the lower limit of normality of basal cortisol levels and the horizontal line shows the cut-off value for normal cortisol responses after $1 \mu \mathrm{g} \mathrm{ACTH.}$

F-test. Correlations between basal and peak cortisol levels, and peak cortisol responses for each test were calculated by regression analysis. $P$ values $<0.05$ were considered significant.

\section{Results}

In normal subjects $1 \mu \mathrm{g} \mathrm{ACTH}$ injection (Fig. 1) significantly $(P<0.001)$ increased mean cortisol levels from a baseline of $393 \pm 43 \mathrm{nmol} / \mathrm{I}$ to a peak of $770 \pm 41 \mathrm{nmol} / \mathrm{I}$ (range 541-1215 nmol/l). All healthy volunteers showed a cortisol rise greater than $500 \mathrm{nmol} / \mathrm{l}$ : the peak level was obtained at $30 \mathrm{~min}$ in 10 subjects, at $40 \mathrm{~min}$ in 7 subjects and at $60 \mathrm{~min}$ in only 1 case.

Seven of the fifty-seven patients with hypothalamicpituitary disorders (12\%) showed basal cortisol levels $(62 \pm 19 \mathrm{nmol} / \mathrm{l})$ below the normal limits. Following $1 \mu \mathrm{g} \mathrm{ACTH} \mathrm{(Fig.} \mathrm{1)} 44$ patients had a cortisol response similar to that in normal subjects, i.e. greater than $500 \mathrm{nmol} / \mathrm{l}$ : mean cortisol concentration rose from $332 \pm 17$ to $769 \pm 24 \mathrm{nmol} / \mathrm{l}(\mathrm{P}<0.001$; peak range $550-1304 \mathrm{nmol} / \mathrm{l})$. On the other hand, in 13 patients $(23 \%)$ serum cortisol response (from $124 \pm 23$ to $312 \pm 46 \mathrm{nmol} / \mathrm{l}$, peak range $10-484 \mathrm{nmol} / \mathrm{l}$ ) was significantly lower than that in normal subjects $(\mathrm{P}<0.001)$. The peak cortisol occurred at $30 \mathrm{~min}$ in $51 \%$ of the patients, at $40 \mathrm{~min}$ in $37 \%$ and at $60 \mathrm{~min}$ in the remaining patients.

An impaired response to ACTH was present in 7 patients with low morning cortisol levels (10-

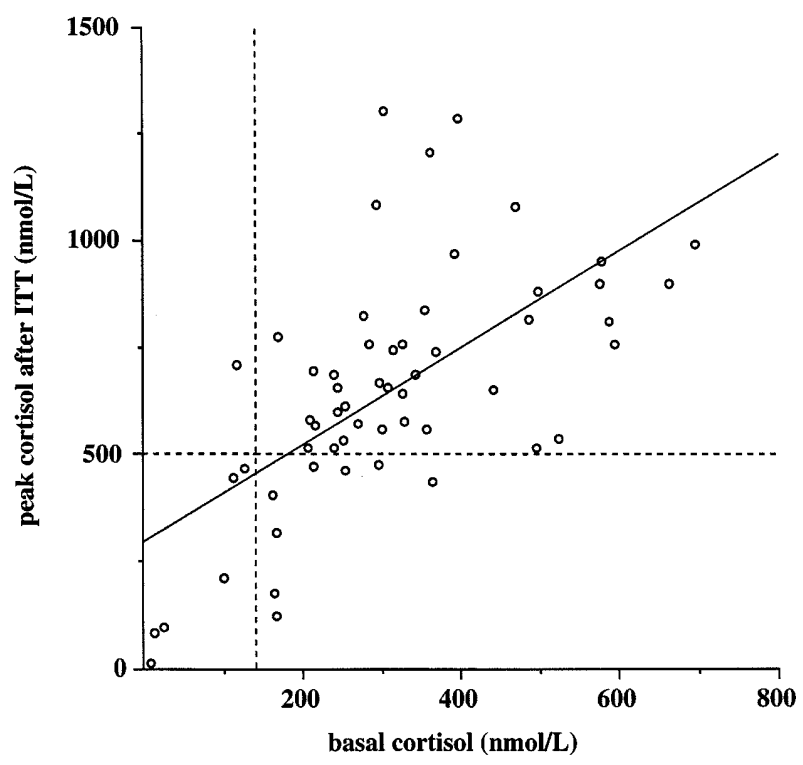

Figure 3 Correlation between peak serum cortisol concentrations after ITT and basal cortisol levels in 57 patients with hypothalamicpituitary diseases $(r=0.64, P<0.001)$. Dotted lines indicate normal ranges: the vertical line shows the lower limit of normality of basal cortisol levels and the horizontal line shows the cut-off value for normal cortisol responses after ITT.

$127 \mathrm{nmol} / \mathrm{l})$, and also in 6 patients with basal values at the lower limit of normality (155-243 nmol/l) (Fig. 2). A positive correlation between basal and peak cortisol levels was found $(r=0.74, \mathrm{P}<0.001)$.

The insulin test induced a normal cortisol rise (from $352 \pm 21 \mathrm{nmol} / \mathrm{l}$ to $763 \pm 32 \mathrm{nmol} / \mathrm{l}, \mathrm{P}<0.001$; peak range $514-1303 \mathrm{nmol} / \mathrm{l}$ ) in 43 out of 57 patients. An impaired cortisol response (from a baseline of $173 \pm 37 \mathrm{nmol} / \mathrm{l}$ to $303 \pm 48 \mathrm{nmol} / \mathrm{l}$, peak range $10-$ $487 \mathrm{nmol} / \mathrm{l}$ ) was observed in the remaining 14 patients (25\%).

Figure 3 shows that an impaired response to ITT was found in 6 patients with low basal cortisol levels (10$126 \mathrm{nmol} / \mathrm{l})$, and also in 8 patients with low/normal or normal baseline values $(165-365 \mathrm{nmol} / \mathrm{l})$; only 1 patient with a reduced baseline cortisol $(118 \mathrm{nmol} / \mathrm{l})$ showed a normal response to ITT. A positive correlation between basal and peak cortisol levels was found $(r=0.64, P<0.001)$.

The responsiveness to ITT was compared with that obtained after the $1 \mu \mathrm{g} \mathrm{ACTH}$ test (Fig. 4). Forty patients positively responded to both tests; ten patients failed both challenges, while four patients who passed the ACTH test failed the ITT. However, three patients who failed the ACTH test passed the ITT. It is worth noting that the 23 patients (out of 57 patients (40\%)) who had a cortisol peak greater than $750 \mathrm{nmol} / \mathrm{l}$ after $1 \mu \mathrm{g} \mathrm{ACTH}$ always showed a normal responsiveness to ITT. Out of the 15 patients who were receiving steroid replacement therapy, 10 failed the $1 \mu \mathrm{g} \mathrm{ACTH}$ and 12 the insulin test. A positive correlation between peak cortisol levels after 


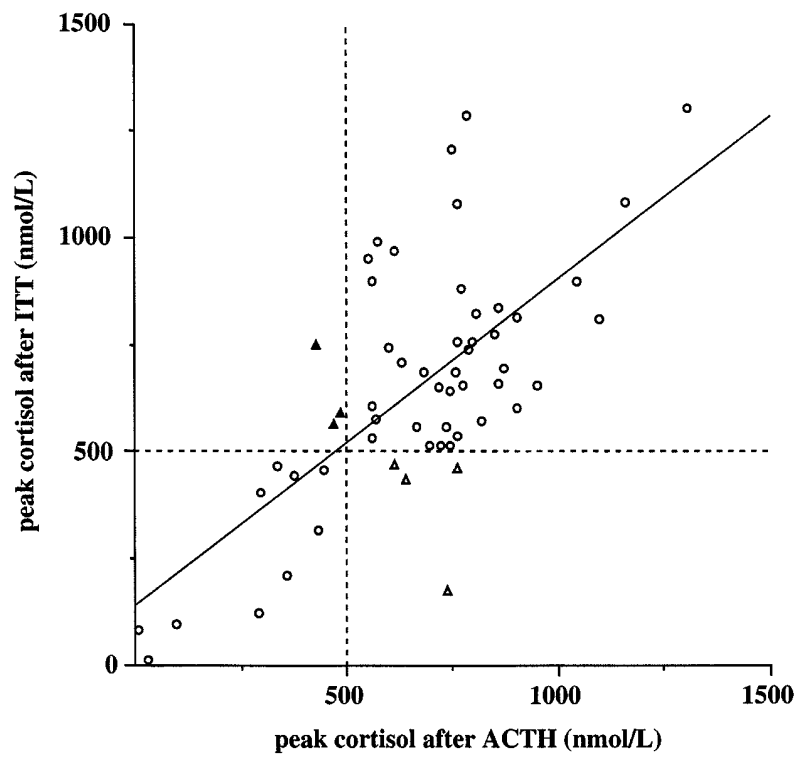

Figure 4 Correlation between peak serum cortisol responses after ITT and after $1 \mu \mathrm{g} \mathrm{ACTH}$ in 57 patients with hypothalamic-pituitary diseases $(r=0.68, P<0.001)$. Dotted lines indicate the cut-off value for normal cortisol responses after ACTH and ITT. The triangles show 7 patients with discrepant results, i.e. the 3 patients who failed the ACTH test and passed the ITT (closed triangles), and the 4 patients who passed the ACTH test but failed the ITT (open triangles).

ACTH and those after insulin was found $(r=0.68$, $P<0.001)$.

Assuming a $100 \%$ accuracy of ITT, the $1 \mu \mathrm{g} \mathrm{ACTH}$ test yielded a $71 \%$ sensitivity and a $93 \%$ specificity. The positive predictive value was $77 \%$ and the negative predictive value was $91 \%$.

\section{Discussion}

The evaluation of HPA function is of great importance in patients with hypothalamic-pituitary disease in order to establish the need for corticosteroid replacement therapy. It is known that the corticotropin challenge does not assess the entire axis and normal responses have been observed despite deficient responsiveness to insulin; moreover, metyrapone is not widely available owing to local restrictions, and even the reliability of the $250 \mu \mathrm{g} \mathrm{ACTH}$ test has recently been questioned (23). Since reported failures have been very rare (24), the ITT is considered the best method for detecting secondary hypoadrenalism, provided that the magnitude of cortisol release in response to stress is superimposable on that physiologically evoked by different stressful events. Recently, it has been suggested that stimulation with low doses of ACTH performs as well as the insulin test in the diagnosis of secondary adrenal insufficiency $(14-16,18)$.

As already reported $(11,12,15)$, the present study confirms that the administration of $1 \mu \mathrm{g} \mathrm{ACTH}$ is able to induce a significant cortisol rise in healthy subjects after
30-40 min. In agreement with previous authors who defined the cut-off value for peak cortisol after $1 \mu \mathrm{g}$ ACTH as $497-500 \mathrm{nmol} / \mathrm{l}(11,15,18,25)$, all our normal controls showed a peak greater than $500 \mathrm{nmol} / \mathrm{l}$ and this limit was considered as the 'pass' criterion for the test.

An impairment of cortisol responsiveness to ACTH was observed in $23 \%$ of our patients with hypothalamic- pituitary disease. Interestingly, the ACTH stimulation also allowed the diagnosis of hypoadrenalism in 6 out of 57 patients (10.5\%) with low/normal basal cortisol levels, indicating the poor value of a single morning determination in diagnosing adrenal failure. Indeed, when baseline cortisol is at the lower limits of normality, a stimulation test is mandatory, as confirmed by the finding of a positive responsiveness to ACTH in one woman with a low basal cortisol level.

In our series the insulin test revealed HPA dysfunction in $25 \%$ of patients, in agreement with previous data (5, $26,27)$. In agreement with the response to the ACTH challenge, impaired responses were also found in patients with low/normal basal cortisol, confirming the necessity of further dynamic testing before instituting steroid replacement therapy in such cases.

Using the cut-off value of $500 \mathrm{nmol} / \mathrm{l}$ for acceptable cortisol responses to either ACTH or insulin $(4,11,15$, $21,22)$, concordant results were present in 50 out of 57 patients $(88 \%)$ who underwent both tests; moreover, there was a positive correlation between the responses after $1 \mu \mathrm{g} \mathrm{ACTH}$ and after insulin tests, as previously found (16). Contrary to the findings of Rasmuson et al. (16) who did not observe any discrepancy between tests, in our study some discordant results were obtained. In fact, 4 patients, operated on 5-48 months previously and without recent ACTH deprivation, passed the low dose test but failed the ITT, as occasionally reported by others (18): this finding militates against a good sensitivity of the $1 \mu \mathrm{g}$ challenge. In contrast, only 3 patients who failed the low dose ACTH test positively responded to insulin, in agreement with similar findings in 2 patients reported by Tordjman et al. (15). This observation suggests that $1 \mu \mathrm{g}$ ACTH is able to reveal a presumably mild hypoadrenalism that had been overcome by the more powerful stimulus of hypoglycemic stress, as described in steroid-treated patients (19).

Notably, the 23 out of 57 patients in whom $1 \mu \mathrm{g}$ ACTH increased cortisol levels above $750 \mathrm{nmol} / \mathrm{l}$, invariably passed the ITT. Since all patients here investigated had been operated on at least 1 month before testing and thus did not have any acute pituitary dysfunction, the unpleasant insulin challenge could have been avoided in a substantial number of cases (40\%). On the whole, assuming the accuracy of the insulin test to be $100 \%$, the $1 \mu \mathrm{g} \mathrm{ACTH}$ challenge had a sensitivity of $71 \%$ and a specificity of $93 \%$.

Although a single morning cortisol measurement is of poor value in assessing the HPA axis, all patients with levels below $100 \mathrm{nmol} / \mathrm{l}$ failed both tests, confirming 
that a very low baseline cortisol strongly suggests HPA insufficiency (26-28). In contrast, normal HPA function was recognized in all patients with basal cortisol above $400 \mathrm{nmol} / \mathrm{l}$ who showed positive responses to tests.

In conclusion, the present study confirms that in patients with hypothalamic-pituitary disease the $1 \mu \mathrm{g}$ ACTH test is a useful, safe and inexpensive tool for the initial assessment of HPA function; particularly, it seems appropriate for exclusion of adrenal insufficiency in outpatients. In fact, it replaces the need for ITT when the peak cortisol response is greater than $750 \mathrm{nmol} / \mathrm{l}$, strongly predicting a normal function of the axis. The finding of very low cortisol basal levels, indicating an overt hypoadrenalism, also makes the hypoglycemic stress unnecessary. In the grey zone within these limits the ITT is mandatory and its important role in the recognition of secondary adrenal failure is further confirmed.

\section{Acknowledgements}

This work was partially supported by grants from Ospedale Maggiore IRCCS, Milano and from MURST, Roma (no. 9706151106). We thank Mrs Silvia Macchi for her skilled technical assistance.

\section{References}

1 Lindholm J, Kehlet $H$, Blichert-Toft $M$, Dinesen B \& Riishede J. Reliability of the 30-minute ACTH test in assessing hypothalamic-pituitary-adrenal function. Journal of Clinical Endocrinology and Metabolism 197847 272-274.

2 Nelson I \& Tindall V. A comparison of the adrenal response to hypoglycemia, metyrapone and ACTH. American Journal of Medical Sciences 1978275 165-172.

3 Lindholm J \& Kehlet $\mathrm{H}$. Re-evaluation of the clinical value of the $30 \mathrm{~min}$ ACTH test in assessing the hypothalamic-pituitaryadrenocortical function. Clinical Endocrinology 198726 53-59.

4 Stewart PM, Seckl JR, Corrie J, Edwards CRW \& Padfield PL. A rational approach for assessing the hypothalamo-pituitaryadrenal axis. Lancet 1988 i 1208-1210.

5 Hurel SJ, Thompson CJ, Watson MJ, Harris MM, Baylis PH \& Kendall-Taylor P. The short Synacthen and insulin stress test in the assessment of the hypothalamic-pituitary-adrenal axis. Clinical Endocrinology 199644 141-146.

6 Brost GC, Michenfelder HJ \& O'Brian JT. Discordant cortisol response to exogenous ACTH and insulin-induced hypoglycemia in patients with pituitary disease. New England Journal of Medicine 1982306 1462-1464.

7 Reschini E, Catania A \& Giustina G. Plasma cortisol response to ACTH does not accurately indicate the state of the hypothalamicpituitary-adrenal axis. Journal of Endocrinological Investigation $19825259-261$.

8 Cunningham SK, Moore A \& McKenna TJ. Normal cortisol response to corticotropin in patients with secondary adrenal failure. Archives of Internal Medicine 1983143 2276-2279.

9 Ammari F, Issa BG, Millward E \& Scanlon MF. A comparison between short ACTH and insulin stress tests for assessing hypothalamo-pituitary-adrenal function. Clinical Endocrinology 199644 473-476.

10 Crowley S, Hindmarsh PC, Holownia P, Honour JW \& Brook CGD. The use of low doses of ACTH in the investigation of adrenal function in man. Journal of Endocrinology 1991130 475-479.

11 Dickstein G, Shechner C, Nicholson WE, Rosner I, Shen-Orr Z A dawi $\mathrm{F}$ et al. Adrenocorticotropin stimulation test: effects of basal cortisol level, time of day, and suggested new sensitive low dose test. Journal of Clinical Endocrinology and Metabolism 1991 72 773-778.

12 Daidoh H, Morita H, Mune T, Murayama M, Hanafusa J, Ni H et al. Responses of plasma adrenocortical steroids to low dose ACTH in normal subjects. Clinical Endocrinology 199543 311-315.

13 Oelkers W. Dose- response aspects in the clinical assessment of the hypothalamo- pituitary-adrenal axis, and the low-dose adrenocorticotropin test. European Journal of Endocrinology 1996135 27-33.

14 Dickstein G, Arad E \& Shechner C. Low-dose ACTH stimulation test. The Endocrinologist 19977 285-293.

15 Tordjman K, Jaffe A, Grazas N, Apter C \& Stern N. The role of the low dose $(1 \mu \mathrm{g})$ adrenocorticotropin test in the evaluation of patients with pituitary diseases. Journal of Clinical Endocrinology and Metabolism 199580 1301-1305.

16 Rasmuson S, Olsson T \& Hagg E. A low dose ACTH test to assess the function of the hypothalamo- pituitary-adrenal axis. Clinical Endocrinology 199644 151-156.

17 Shankar RR, Jakacki RI, Haider A, Lee MW \& Pescovitz OH. Testing the hypothalamic-pituitary-adrenal axis in survivors of childhood brain and skull-based tumors. Journal of Clinical Endocrinology and Metabolism 199782 1995-1998.

18 Weintrob N, Sprecher E, Josefsberg Z, Weininger C, AurbachKlipper Y, Lazard D et al. Standard and low-dose short adrenocorticotropin test compared with insulin-induced hypoglycemia for assessment of the hypothalamic-pituitary-adrenal axis in children with idiopathic multiple pituitary hormone deficiencies. Journal of Clinical Endocrinology and Metabolism 199883 88-92.

19 BroideJ, Soferman R, Kivity S, Golander A, Dickstein G, Spirer Zet $a l$. Low-dose adrenocorticotropin test reveals impaired adrenal function in patients taking inhaled corticosteroids. Journal of Clinical Endocrinology and Metabolism 19954 1243-1246.

20 Wilson AM, McFarlane LC \& Lipworth B]. Effects of low and high doses of inhaled flunisolide and triamcinolone acetonide on basal and dynamic measures of adrenocortical activity in healthy volunteers. Journal of Clinical Endocrinology and Metabolism 19983 922-925.

21 Littley MD, Gibson S, White A \& Shalet SM. Comparison of the ACTH and cortisol responses to provocative testing with glucagon and insulin hypoglycaemia in normal subjects. Clinical Endocrinology 198931 527-533.

22 Grinspoon SK \& Biller BMK. Laboratory assessment of adrenal insufficiency. Journal of Clinical Endocrinology and Metabolism 199479 923-931.

23 Mukherjee JJ, Jacome de Castro J, Kaltsas G, A fshar F, Grossman $A B$, Wass JAH et al. A comparison of the insulin tolerance/glucagon test with the short ACTH stimulation test in the assessment of the hypothalamo-pituitary-adrenal axis in the post-operative period after hypophysectomy. Clinical Endocrinology 199747 51-60.

24 Tsatsoulis A, Shalet SM, Harrison J, Ratcliffe WA, Beardwell CG \& Robinson EL. Adrenocorticotropin deficiency undetected by standard dynamic test of the hypothalamic-pituitary-adrenal axis. Clinical Endocrinology 198828 225-232.

25 Dickstein G, Spigel D, Arad D \& Shechner C. One microgram is the lowest ACTH dose to cause a maximal cortisol response. There is no diurnal variation of cortisol response to submaximal ACTH stimulation. European Journal of Endocrinology 1997137 172-175.

26 Pavord SR, Girach A, Price DE, A bsalom SR, Falconer-Smith I \& Howlett TA. A retrospective audit of the combined pituitary function test, using the insulin stress test, TRH and GnRH in a district laboratory. Clinical Endocrinology 199236 135-139.

27 Jones SL, Trainer PJ, Perry L, Wass JA H, Besser GM \& Grossman A. An audit of the insulin tolerance test in adult subjects in an acute investigation unit over one year. Clinical Endocrinology 199441 $123-128$.

28 Hagg $E$, Asplund $K \&$ Lithner F. Value of basal plasma cortisol assays in the assessment of pituitary-adrenal insufficiency. Clinical Endocrinology 198726 221-226.

Received 23 July 1998

Accepted 13 August 1998 